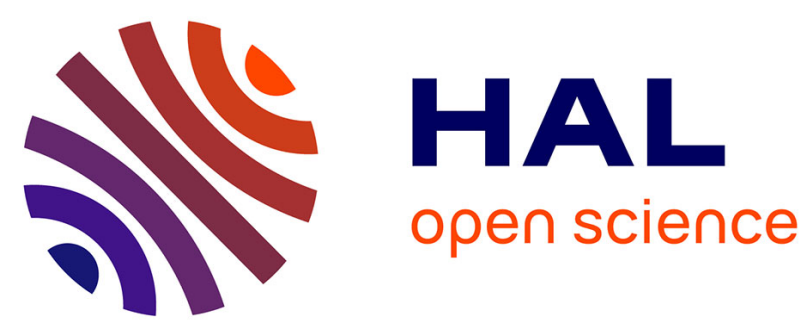

\title{
Solvent-free mechanochemical route for green synthesis of pharmaceutically attractive phenolhydrazones
}

\author{
Paulo F. M. Oliveira, Michel Baron, Alain Chamayou, Christiane
}

André-Barrès, Brigitte Guidetti, Michel Baltas

\section{- To cite this version: \\ Paulo F. M. Oliveira, Michel Baron, Alain Chamayou, Christiane André-Barrès, Brigitte Guidetti, et al.. Solvent-free mechanochemical route for green synthesis of pharmaceutically attractive phenolhy- drazones. RSC Advances, 2014, 4 (100), p.56736-56742. 10.1039/c4ra10489g . hal-01625025}

\section{HAL Id: hal-01625025 \\ https://hal.science/hal-01625025}

Submitted on 8 Nov 2019

HAL is a multi-disciplinary open access archive for the deposit and dissemination of scientific research documents, whether they are published or not. The documents may come from teaching and research institutions in France or abroad, or from public or private research centers.
L'archive ouverte pluridisciplinaire HAL, est destinée au dépôt et à la diffusion de documents scientifiques de niveau recherche, publiés ou non, émanant des établissements d'enseignement et de recherche français ou étrangers, des laboratoires publics ou privés. 


\title{
Solvent-free mechanochemical route for green synthesis of pharmaceutically attractive phenol- hydrazones $\dagger$
}

\author{
P. F. M. Oliveira, ${ }^{a}$ M. Baron, ${ }^{\star a}$ A. Chamayou, ${ }^{a}$ C. André-Barrès, ${ }^{b}$ B. Guidetti ${ }^{b}$ \\ and M. Baltas*b
}

A series of hydrazones, as potential therapeutic agents, were successfully synthesized in a vibratory ball-mill from various substituted organic hydrazines and phenol aldehydes. The degree of conversion was increased by high electronic density on the amino group of the hydrazine reactant, as well as low steric hindrance around both reactive sites. In this particular case, the flexibility of the chain bearing the amino reactive site of hydrazine was highlighted as a factor influencing the reaction rate. The results showed that hydrazones could be obtained with more than a $99 \%$ transformation, without concurring by-products. This is highly adapted to the synthesis of active pharmaceutical ingredients, requiring a high level of purity. Owing to the fact that neither an environmentally unadvisable reagent nor additives or catalysts were added to achieve the transformation, this synthesis provides a good example and a prefiguration of an efficient green pharmaceutical process.

\section{Introduction}

Nowadays there is an urgent need for research and industry to invent new, clear and less expensive ways to produce chemicals. All areas of chemistry play important roles in this context. Among them, catalysis and solvent-free systems are the most explored, using different types of energy to perform reactions, including microwave, ultrasound, photochemical and mechanical procedures..$^{1-3}$

Mechanochemistry has been used for inorganic materials for a long time to generate different phases in the area of mechanical alloying., ${ }^{45}$ More recently, the possibility of using mechanical energy to synthesize organic molecules in milling devices has opened up a new area of chemistry. Current applications and advances of mechanochemistry can be seen in almost all kinds of organic transformations such as co-crystal formation and classic organic syntheses. ${ }^{6,7}$

In the pharmaceutical area, where the concept of Green Pharmacy is more newsworthy than ever, ${ }^{8-13}$ the mechanical action is used to produce transformations in molecular crystals to enhance properties such as tableting and bioavailability. ${ }^{\mathbf{1 4 - 1 7}}$ But, the applications of mechanochemistry for pharmaceuticals go beyond associations at a supramolecular level, including the

${ }^{a}$ Université de Toulouse, Mines-Albi, CNRS UMR 5302, Centre Rapsodee, Campus Jarlard, 81013 Albi Cedex 09, France. E-mail: baron@mines-albi.fr

${ }^{b}$ Université de Toulouse, UPS, CNRS UMR 5068, LSPCMIB, 118 Route de Narbonne, 31062, Toulouse Cedex 09, France.E-mail: baltas@chimie.ups-tlse.fr improvement of active ingredient synthesis, as well as the design of new potential ones. As an example, Tan et al. prepared sulfonyl-(thio)ureas, including anti-diabetic drugs, via mechanosynthesis. ${ }^{18}$ But, in particular, mechanochemistry was used to develop nitrogen-containing heterocycles, a series well represented in many therapeutic classes. For example, phthalazoles, ${ }^{19}$ phenazines,${ }^{20}$ pyrazoles, pyridazinones, ${ }^{21}$ and pyrroles ${ }^{22}$ were obtained by mechanosynthesis, but non-heterocyclic nitrogen-containing molecules were also synthesized under mechanical solid-state and solvent-free conditions, including peptides, ${ }^{23-25}$ imines, azomethines, ${ }^{26,27}$ azines, ${ }^{21}$ enamines ${ }^{28}$ and hydrazones. ${ }^{28-30}$ In addition to being a green process, many other attractive aspects of working without solvent were reported, as the yield was usually higher than $90 \%$ and generally $\geq 99 \%$, and the selectivity reduced the formation of byproducts and eliminated purification steps for pharmaceutical ingredients and medicines.

The potential applications of hydrazones as antioxidant agents, against sepsis and tuberculosis, as vasodilators to treat hypertension, and as antitumor agents, show that the hydrazone class is considered an important one for new drug development. ${ }^{31-34}$ Until now, they have been mainly synthesized by classical methods, involving the reaction of a hydrazine with a carbonyl compound under reflux conditions in diluted media. Industrial drawbacks are the amount of solvent used (ethanol or toluene usually), inducing a lot of waste, and the thermal energy needed for an overall time consuming process. In addition, water formation during the reaction may induce incomplete conversions. There are other reports of hydrazones and derivatives being formed under solvent-free conditions using 
microwave irradiation in short times with high yields, but sometimes the use of a small amount of solvent is required and the amount of reagents used is often around $0.5-5 \mathrm{mmol} .{ }^{35-38} \mathrm{In}$ this context Hajipour et al. reported for the first time the synthesis of hydrazones and semicarbazone derivatives in quantitative yields by milling in mortar with sodium hydroxide and silica gel as a solid support acting as a facilitator..$^{38}$ Later on, Kaupp et al. obtained benzoylhydrazone by milling stoichiometric amounts of benzhydrazine and solid aldehyde or ketone. ${ }^{28}$ Similarly, using the kneading method it was possible to produce phenylhydrazones in a melt system. ${ }^{29}$ More recently, Nun et al. carried out the synthesis of hydrazones in quantitative yields by milling a large variety of protected hydrazines with equimolar amounts of carbonyl compounds. The subsequent $\mathrm{N}$ alkylation of some of them was also reported by the same authors. ${ }^{30}$

Herein we report the mechanosynthesis of a phenolhydrazone series obtained by a solid-state solvent-free reaction of an aldehyde with the respective hydrazine. We have already synthesized phenolhydrazones using classical methods and shown they possess strong antioxidant properties and cytoprotective effects against oxidized Low Density Lipoproteins (LDL) that play a key role in the atherogenesis process and cardiovascular diseases. ${ }^{39}$ The mechanosyntheses of the hydrazones were carried out on $2 \mathrm{~g}$ of reactants with strictly one equivalent of each partner, in a vibratory ball-mill with a single ball for an average time of 4 hours at room temperature.

\section{Results and discussion}

The classical solvation methods to synthesize hydrazones are generally carried out at low concentration, and require times of 3 to 24 or even 48 hours under reflux of toluene or ethanol in order to obtain good yields. In this framework we applied mechanical energy using a vibratory mill to produce 24 hydrazones (Table 1). With an aim to compare the respective reactivities of reactants under mechanochemical conditions, a series of hydrazones were synthesized, some of which have already been described using classical methods by our group. $^{31,39}$ Scheme 1 shows the general solid-state mechanosynthesis of hydrazones by reacting a hydrazine and an aldehyde.

Once the objective of the work was to investigate the production of hydrazones in the solid-state, the mandatory condition for the choice of reagents was a melting point above the temperature of synthesis. As the reactions were carried out at room temperature all the reagents presented in Table 1 fulfill the requirement. The syntheses with hydralazine hydrochloride were performed in the presence of 1 equivalent of triethylamine (TEA) in order to liberate the base from its respective salt. Table 1 also summarizes, for each synthesis, the time of grinding and the conversion obtained by analysis of ${ }^{1} \mathrm{H}$ NMR spectra. TLC showed the consumption of the reagents and the consequent appearance of the hydrazone, which was confirmed by ${ }^{1} \mathrm{H}$ and ${ }^{13} \mathrm{C}$ NMR analysis, demonstrating final conversions (and thus yields) of up to $99 \%$ depending on the aldehyde-hydrazine couple, and no byproducts were detected. In addition, the progress of the reactions can be followed by Raman analysis. This technique could be a rapid way to control mechanochemical reactions without using solvents as reported elsewhere. ${ }^{40}$ As an example, the reaction of syringaldehyde with benzyl carbazate is presented in Fig. 1.

The hydrazones listed in Table 1 were obtained with a high transformation ratio in grinding times of $4 \mathrm{~h} .{ }^{1} \mathrm{H}$ NMR spectra revealed conversions with respect to the aldehydes and hydrazines of over $90 \%$ in almost all the explored syntheses and no byproducts were found. In Table 1 we have also introduced conversions (if quantitative) and yields (where purification was needed) for a series of hydrazones obtained by us under classical conditions ( $1 \mathrm{mmol}$ of each reagent $/ 30 \mathrm{~mL}$ of solvent under reflux for $6-24 \mathrm{~h}) .^{31,39}$ For the hydralazine hydrochloride reagent the classical reaction was performed in the absence of base (triethylamine) and the hydrazone hydrochloride was isolated.

The mechanochemical route, maybe due to its original mechanism, seems to be more efficient when comparing the results with the classical ones under reflux and heat. With regard to the couplings with isoniazid, hydrazones are obtained with analogous conversions and yields using the classical and mechanochemical methods. The same is true for benzyl carbazate where the conversions and yields are almost quantitative in both cases. For 2-hydrazinobenzothiazole, reactions appear better under classical conditions, while for hydralazine hydrochloride and 3-aminorhodanine the mechanochemical route appears much more optimal. It is worth pointing out that with regard to hydrazone formation with 3-aminorhodanine, conversions and yields can be greatly improved with the mechanochemical process but also by performing the later reaction for $8 \mathrm{~h}$ (this was tested with this hydrazine as an example); almost quantitative conversions and yields (no further purification needed) were obtained. This example is a clear illustration of the potential of mechanochemistry as a green route to synthesize active pharmaceutical ingredients. The reactivity of the hydrazines observed by the mechanochemical route could be explained as a result of electronic effects and solid form influences.

\section{Electronic effects}

Substitution patterns on hydrazines $\left(\mathrm{R}^{1}, \mathrm{R}^{2}\right)$ may influence the electronic effects and distribution at the terminal $\mathrm{NH}_{2}$ functionality, thus modifying its reactivity. In order to get an insight into the reactivity of the different hydrazines we determined these effects. Table 2 shows the results of natural bond orbital $(\mathrm{NBO})^{41}$ analysis to access the partial atomic charges of the hydrazines, which was performed in the B3LYP/6-311+G(d,p $)^{42}$ level of theory for the structures of hydrazines obtained by density functional theory (DFT), calculated with Gaussian 09 software. ${ }^{43}$ In a preliminary approach, these simulations were used to attribute values to pure chemical reactivity, making the following comparison possible: the more negative the charge, the more nucleophilic or basic the atom. The most striking difference is observed for 3-aminorhodanine where the charge density on the terminal $\mathrm{NH}_{2}$ group of the hydrazine appears to be much less than for all other compounds. 
Table 1 Solids aldehydes (column) and hydrazines (line) used for the synthesis of hydrazones and degree of conversion ${ }^{a}$ for corresponding hydrazones for 4 hours of grinding as well as the yields ${ }^{b}$ from classical method in parentheses

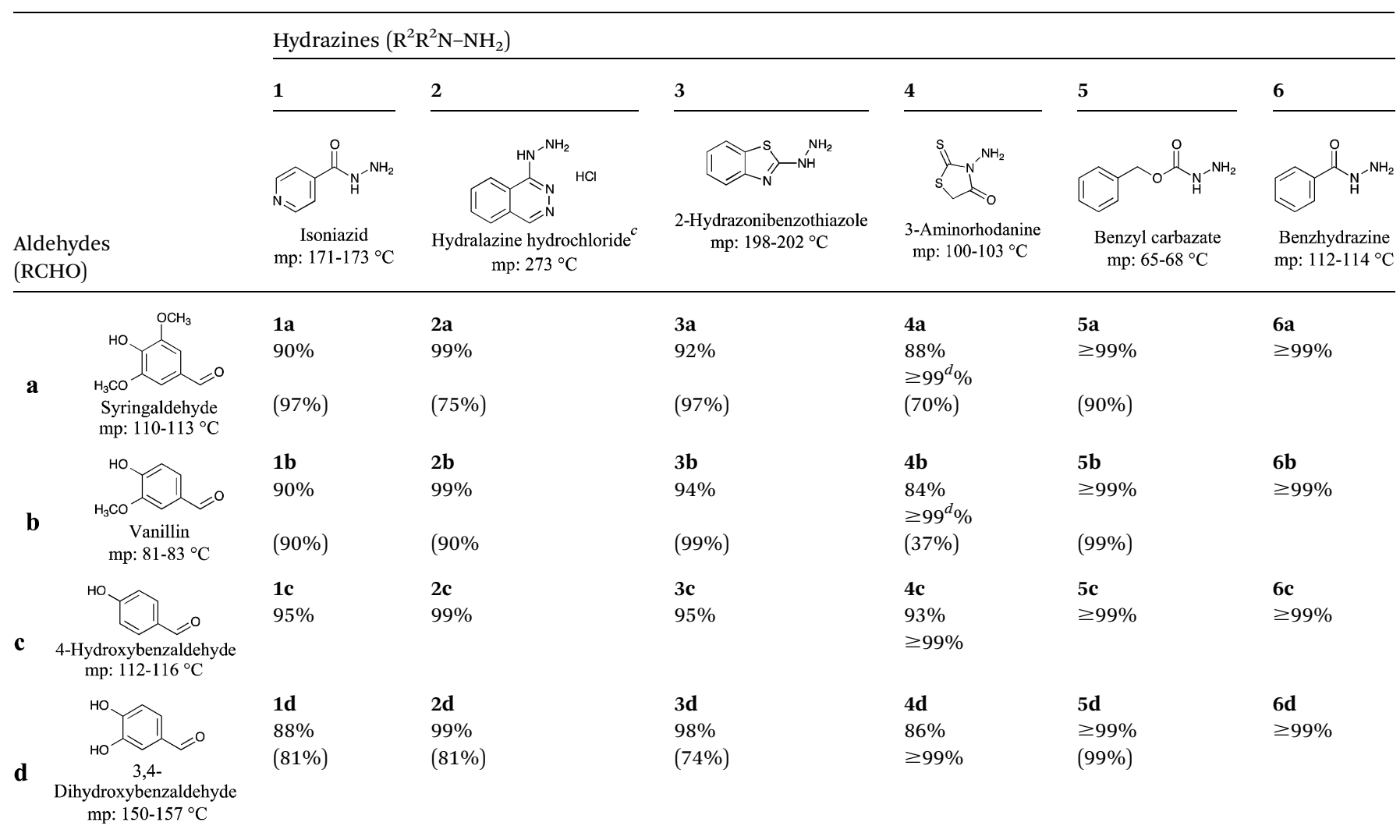

${ }^{a}$ Determined by ${ }^{1} \mathrm{H}$ NMR. In reactions where ${ }^{1} \mathrm{H}$ NMR indicated a conversion lower than quantitative, the degree of conversion was calculated from the corresponding NMR intensities of the product and the unreacted aldehyde or hydrazine. ${ }^{b}$ Yields obtained by the classical method with 1 mmol/ $30 \mathrm{~mL}$ under reflux in times from 8 to $24 \mathrm{~h}$ (see ref. 38 and 46). ${ }^{c}$ These syntheses with hydralazine hydrochloride were performed in presence of 1 equivalent of triethylamine (TEA) and the hydrazone was obtained after washing with water to eliminate the TEA salt. ${ }^{d}$ Conversion after 8 hours of grinding.

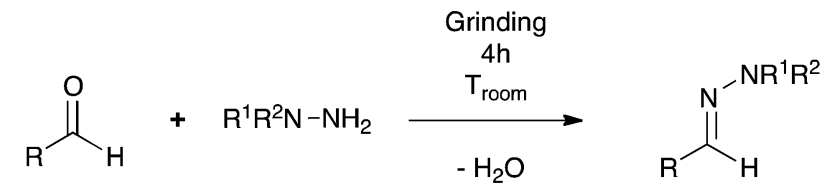

Scheme 1 General synthesis of hydrazones in the solid-sate by cogrinding of a hydrazine and an aldehyde.

It is reasonable to assume in this case that this effect might explain the lack of reactivity and the low yields especially obtained under classical conditions (70\% and 37\%). The effect is more pronounced in solution than under mechanochemical conditions, where total conversion is achieved after a more prolonged time. For the other hydrazines used, the charge density differences are small, in accordance with analogous yields obtained under solution conditions.

The charge density on the reactive part of the aldehydes used was also determined. The values obtained under the same level of theory do not indicate any strong preference in favor of one of them (all values are between 0.0413 and 0.0414 ). We can thus assume that the conversions/yields of the hydrazones obtained under classical conditions reflect the $\mathrm{NH}_{2}$ reactivity.

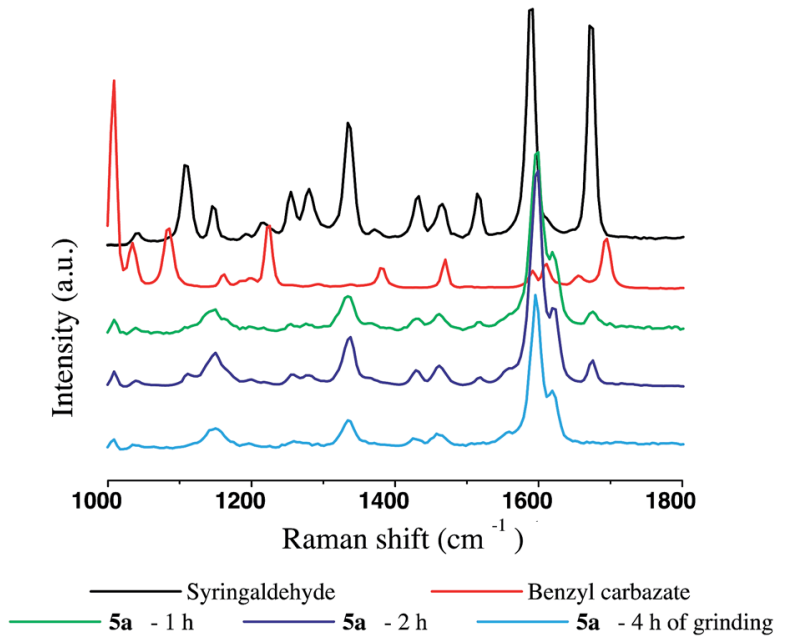

Fig. 1 Raman spectra of hydrazone formation (5a) after 1, 2 and 4 hours of grinding.

Despite the fact that the calculations of partial atomic charges represent a great panoramic for the prevision of the nucleophile sites for the explored cases herein, the hydrazines 
Table 2 Charge density of the $-\mathrm{NH}_{2}$ group from hydrazines

\begin{tabular}{ll}
\hline Hydrazine & Charge density of $-\mathrm{NH}_{2},(\mathrm{NBO})^{a}$ \\
\hline Isoniazid & -0.634 \\
Hydralazine $^{b}$ & -0.637 \\
2-Hydrazinobenzothiazole & -0.628 \\
3-Aminorhodanine & -0.601 \\
Benzyl carbazate & -0.626 \\
Benzhydrazide & -0.637
\end{tabular}

${ }^{a}$ Natural bond orbital (NBO) ${ }^{41}$ analysis performed in the B3LYP/6$311+\mathrm{G}(\mathrm{d}, \mathrm{p})^{42}$ level of theory for the structures of hydrazines obtained by density functional theory (DFT) calculated with Gaussian 09 software..$^{43}$ NBO was performed for the hydralazine base.

do not follow the expected results in some cases when mechanochemical conditions are used. This is especially the case for isoniazid, benzhydrazide and benzyl carbazate. Based on this outlook, it is believed that these solid-state mechanosyntheses are not only guided by electronic aspects but also solid characteristics such as the crystal packing, solid form, density, and finally, in summary, the accessibility of reactive sites in organic solids.

\section{The solid-state role}

The mechanisms of solid-state transformations during grinding have been generally attributed to the formation of eutectic melts ${ }^{44}$ molecular transport through surfaces due to sublimation $^{45,46}$ or in the bulk of material ${ }^{47,48}$ and to reactions mediated by amorphous or metastable crystalline phases. ${ }^{49,50}$ In this work we focused on the properties of raw materials that could facilitate a reaction or make it harder. In solid crystals, molecules are not free as in gas or solution, but are trapped in a lattice trying to form the most stable arrangement. All other surrounding molecules interact mainly by van der Waals' forces and/or H-bonding, which govern the crystal packing. In this section some properties of the solid hydrazines are used to discuss the role of the solid-state on the conversion and reactivity. Crystal properties of some hydrazines, such as crystallographic data, intermolecular interactions represented here by hydrogen bonds and absolute density, were employed to postulate a balance between the electronic properties, previously discussed, and the steric effects originating from the solid form.

Intermolecular hydrogen-bonding is responsible for the stabilization of the crystal structure. Therefore, in order to perform a reaction in the solid state it is necessary to dissociate the $\mathrm{H}$-bonds, and, consequently, the stronger the $\mathrm{H}$-bonds, the higher the energy required to dissociate them. DSC measurements were performed, but the melting points and molar $\Delta H_{\text {fus }}$ obtained for the reactants do not explain their reactivity in this study (see Table 3S, ESI $\dagger$ ). On the other hand, as an approximation, FTIR spectrometry was used to investigate the hydrogen bond strength of the starting hydrazines by both the dilution method and temperature variation in the solid state. The stretching vibrations associated with the $\mathrm{NH}_{2}$ group of hydrazines were studied depending on the concentration $(A=f$ (concentration) in solution) or temperature in the solid state $(\nu=f)$, but the results were generally inconclusive, except for with aminorhodanine (the lowest reactive hydrazine by the mechanical route). For this hydrazine, in accordance with literature data, ${ }^{51} \nu_{\mathrm{s}}\left(\mathrm{NH}_{2}\right)$ and $\nu_{\text {as }}\left(\mathrm{NH}_{2}\right)$ modes were observed at 3295 and $3325 \mathrm{~cm}^{-1}$ in the IR spectrum, respectively. Two additional bands were present at $\nu 3149$ and $3233 \mathrm{~cm}^{-1}$, which have been assigned to a combination band of the CO stretching and $\mathrm{NH}_{2}$ bending modes and an overtone of the $1536 \mathrm{~cm}^{-1}$ band, respectively. ${ }^{52}$ In addition, a linear variation of the wavenumber at $\nu 3149 \mathrm{~cm}^{-1}$ was observed as the temperature increased (from 25 to $85{ }^{\circ} \mathrm{C}$ ), demonstrating for this hydrazine the existence of intermolecular interactions in the solid (see Fig. 1S in the ESI $\dagger$ ). On the other hand, the simulated FTIR spectra (in the gas phase at $298 \mathrm{~K}$ ) do not reveal any intramolecular H-bonds (see Table $1 \mathrm{~S}$ in the ESI $\dagger$ ). Some data from the literature also support this discussion. Recent studies have shown that the crystal packing of aminorhodanine is governed by $\mathrm{H}$ bonding. ${ }^{53}$ The molecules are linked by $\mathrm{N}-\mathrm{H} \cdots \mathrm{O}, \mathrm{N}-\mathrm{H} \cdots \mathrm{N}$ and $\mathrm{N}-\mathrm{H} \cdots \mathrm{S}$ hydrogen bonds, forming a three-dimensional network that probably reduces the nitrogen reactivity. Similarly, a recent investigation of the crystal structure of isoniazid showed that predominantly $\mathrm{C}-\mathrm{H} \cdots \mathrm{N}, \mathrm{C}-\mathrm{H} \cdots \mathrm{O}$ and $\mathrm{N}-\mathrm{H} \cdots \mathrm{N}$ types of intermolecular hydrogen-bonding interactions are responsible for the molecular packing of the crystal. ${ }^{54}$ These interactions form an infinite spiral type structure in the crystal. ${ }^{55}$ Molecules also form $\pi-\pi$ interactions in the crystal at a distance of $3.760 \AA$. These intermolecular hydrogen-bonds could help explain the lower than expected reactivity of isoniazid and reduce still more the reactivity of the 3-aminorhodanine. The crystal arrangements of the other hydrazines are probably guided by hydrogen bonds as well, but no study is described in the literature.

In addition to the hydrogen bonding and stacking, the proximity of the molecules must also influence the accessibility of the reactive nitrogen. The density of the hydrazines was used as a first approach to represent the proximity of the molecules. The density values were obtained with a helium pycnometer through the real volume, which does not take the empty spaces into consideration, and are given in Table 3 in $\mathrm{g} \mathrm{cm}^{-3}$.

The density of benzyl carbazate is the smallest at $1.2559 \mathrm{~g}$ $\mathrm{cm}^{-3}$, followed by benzhydrazide, isoniazid, 2-hydrazinobenzothiazole, hydralazine hydrochloride and 3-aminorhodanine with a density of $1.6603 \mathrm{~g} \mathrm{~cm}^{-3}$. Intuitively, a small density could indicate further apart molecules and more

\begin{tabular}{ll}
\hline Table 3 Absolute density $\left(\mathrm{g} \mathrm{cm}^{-3}\right)$ of the solid hydrazines \\
\hline Hydrazine & $\begin{array}{l}\text { Absolute density } \\
\left(\mathrm{g} \mathrm{cm}^{-3}\right)\end{array}$ \\
\hline Isoniazid & 1.4318 \\
Hydralazine hydrochloride & 1.4799 \\
2-Hydrazinobenzothiazole & 1.4525 \\
3-Aminorhodanine & 1.6603 \\
Benzyl carbazate & 1.2559 \\
Benzhydrazide & 1.3006
\end{tabular}


freedom to move. Seen in this way, 3-aminorhodanine has the tighter form and benzyl carbazate the looser one, with its reactivity in the solid state affected by this factor. For 3-aminorhodanine, the higher density further hampers access to the reaction site. Isoniazid also has a higher density than benzyl carbazate and benzhydrazide and is less available in the lattice to react. In the same way that in density charge calculations, 2hydrazinobenzothiazole occupies a midterm in the series of density, the same is found for conversions which are always at about $95 \%$.

One can discuss the influence of the mobility of the hydrazine's reactive site. The chain bearing the reactive $-\mathrm{NH}_{2}$ can move more readily as the chain gets longer, which most likely facilitates its accessibility toward the carbonyl group of the aldehyde. For example, benzyl carbazate presents a longer chain and complementary experiments, not presented in Table 1 , for the synthesis of $\mathbf{5 a}$ a showed conversions of around $88 \%$ and $95 \%$ for 1 and $2 \mathrm{~h}$ grinding, respectively, confirming the ability of benzyl carbazate to react quickly under these conditions. The Raman spectra of these runs and the starting materials in the solid state are presented in Fig. 1. The presence of a hydrazone bond $\mathrm{C}=\mathrm{N}$ at $1600 \mathrm{~cm}^{-1}$ and a notable decrease of the $\mathrm{C}=\mathrm{O}$ band of the aldehyde at $1670 \mathrm{~cm}^{-1}$ when compared with syringaldehyde shows that after only one hour the major part is the product. On the contrary, the partial intracyclic inclusion of the hydrazino group of 3-aminorhodanine acts to reduce the freedom of the reactive site of the hydrazine and the grinding time is extended to $8 \mathrm{~h}$ to attain transformations of around $99 \%$.

Finally, Fig. 2 summarizes the importance of different characteristics of hydrazines potentially acting in these solidstate mechanosyntheses of hydrazones.

Other papers have discussed the electronic effects and crystal packing for solid-state reactivity. It was observed that the products and kinetics are guided by the crystal packing (subject of topochemistry). ${ }^{56}$ Through detailed studies and computer calculations, Gavezzotti had already concluded that a prerequisite for crystal reactivity is the availability of free space around

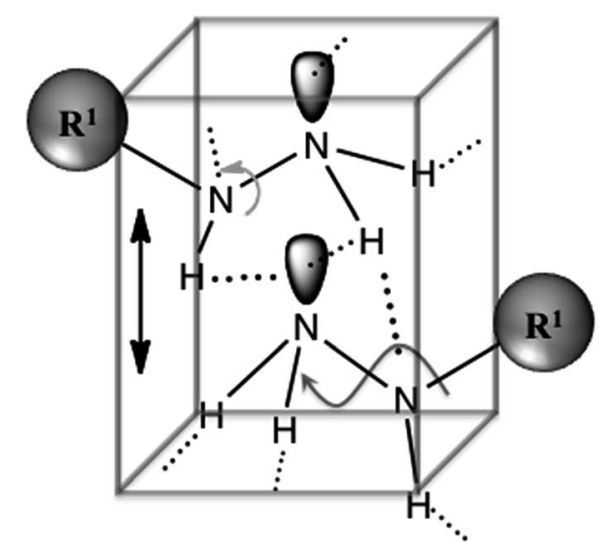

Fig. 2 The electronic and solid-state balance in reactivity of hydrazines. Orbitals are used only to represent $-\mathrm{NH}_{2}$, hydrogen bonds are represented by dotted lines, density by vertical arrows and degree of freedom by curved arrows. the reaction site. ${ }^{57}$ Years later, Sarma et al. discussed the role of free volume of some aldehydes for solid-state bromination and found differences in selectivity from solution. ${ }^{58}$ More recently, it has been demonstrated that the amount and form of energy and how the mechanical energy is applied concerning the mechanochemical systems, strongly influence the products and kinetics. ${ }^{59-61}$ The difference in selectivity of the products from solution and solid syntheses has shown that mechanical energy is capable of surpassing some classical rules in chemistry leading to comprehension of the same molecule in its different states of aggregation and under different perturbations. ${ }^{62-67}$ With regard to the synthesis of hydrazones the results point to a balance between the electronic contributions (orbitals), the strength of hydrogen bonds (dotted lines), the proximity of the molecules, expressed by absolute density (vertical arrow) and the degree of freedom or movement (curved arrows), as suggested in Fig. 2. What is not mentioned is that the mechanical energy is essential to favor the reaction by breaking and destabilizing the solid, which increases the Gibbs free enthalpy, ${ }^{50}$ and by activating on a macro and molecular level.

\section{Conclusions}

Several hydrazones were successfully synthesized via a mechanochemistry route by grinding aldehydes and hydrazines in the solid-state at room temperature. Conversion ratios of $85-99 \%$ were obtained depending on the hydrazine/aldehyde used, but it was demonstrated that the reactions could reach transformations $\geq 99 \%$ by changing the time of grinding, as illustrated in the case of the 3 -aminorhodanine series. This approach seems to be more efficient in the preparation of hydrazones in the solid-state and in larger quantities which are easier to scale up in comparison with reactions carried out in solution, under microwave radiation ${ }^{36-38}$ or using other milling devices. $^{28-31}$

In conclusion, these considerations helped us to understand the reactivity of the hydrazines, which seems to be the result of a balance of electronic and solid effects. It is still appropriate to say that of the hydrazones synthesized in this study, no difference in the final products was found when compared with thermal synthesis under reflux of solvent, due, for example, to another mechanism of reaction or excited state. ${ }^{67}$ The formation of intermediate metastable phases during grinding were not excluded, but not detected. On the other hand, the properties of the raw materials, such as packing guided by hydrogen bonds, density and freedom of the molecule, fitted the results satisfactorily.

This solvent-free synthesis of this series of hydrazones can be anticipated as a rational and powerful way forward for the synthesis of active pharmaceutical ingredients.

\section{Acknowledgements}

We thank Corinne Routaboul for FTIR studies, Laurène Haurie (Plateforme GALA ${ }^{\circledR}$ ) for Raman spectra and Sylvie Del Confetto for DSC measurements. 


\section{Notes and references}

1 R. Varma and H. M. Meshram, Tetrahedron Lett., 1997, 38, 7973.

2 G. Nogendrappa, Resonance, 2002, 11, 64.

3 R. B. N. Baig and R. S. Varma, Chem. Soc. Rev., 2012, 41, 1559.

4 P. Baláž, Int. J. Miner. Process., 2003, 72, 341.

5 N. Burgio, A. Iasonna, M. Magini, S. Martelli and F. Padella, Nuovo Cimento, 1991, 13, 459.

6 S. L. James, C. J. Adams, C. Bolm, D. Braga, P. Collier, T. Friščić, F. Grepioni, K. D. M. Harris, G. Hyett, W. Jones, A. Krebs, J. Mack, L. Maini, a. G. Orpen, I. P. Parkin, W. C. Shearouse, J. W. Steed and D. C. Waddell, Chem. Soc. Rev., 2012, 41, 413.

7 G.-W. Wang, Chem. Soc. Rev., 2013, 42, 7668.

8 M. Baron, Waste Biomass Valorization, 2012, 3, 395.

9 R. Bandichhor, A. Bhattacharya, L. Diorazio, P. Dunn, K. Fraunhoffer, F. Gallou, J. Hayler, M. Hickey, W. Hinkley, D. Hughes, L. Humphreys, B. Kaptein, S. Mathew, T. Rammeloo, P. Richardson and T. White, Org. Process Res. Dev., 2013, 17, 615.

10 W. J. W. Watson, Green Chem., 2012, 14, 251.

11 C. Jimenez-Gonzalez, C. S. Ponder, Q. B. Broxterman and J. B. Manley, Org. Process Res. Dev., 2011, 15, 912.

12 I. Andrews, P. Dunn, J. Hayler, B. Hinkley, D. Hughes, B. Kaptein, K. Lorenz, S. Mathew, T. Rammeloo, L. Wang, A. Wells and T. D. White, Org. Process Res. Dev., 2011, 15, 22.

13 D. J. C. Constable, P. J. Dunn, J. D. Hayler, G. R. Humphrey, J. L. Leazer Jr, R. J. Linderman, K. Lorenz, J. Manley, B. A. Pearlman, A. Wells, A. Zaks and T. Y. Zhang, Green Chem., 2007, 9, 411.

14 A. Delori, T. Friščić and W. Jones, CrystEngComm, 2012, 14, 2350.

15 S. Karki, T. Friščić, L. Fábián, P. R. Laity, G. M. Day and W. Jones, Adv. Mater., 2009, 21, 3905.

16 A. Gil, A. Chamayou, E. Leverd, J. Bougaret, M. Baron and G. Couarraze, Eur. J. Pharm. Sci., 2004, 23, 123.

17 T. Watanabe, S. Hasegawa, N. Wakiyama, A. Kusai and M. Senna, Int. J. Pharm., 2003, 250, 283.

18 D. Tan, V. Štrukil, C. Mottillo and T. Friščić, Chem. Commun., 2014, 50, 5248.

19 M. A. Mikhailenko, T. P. Shakhtshneider and W. V. Boldyrev, Mendeleev Commun., 2007, 17, 315.

20 L. Carlier, M. Baron, A. Chamayou and G. Couarraze, Tetrahedron Lett., 2011, 52, 4686.

21 B. Lee, P. Kang, K. H. Lee, J. Cho, W. Nam, W. K. Lee and N. H. Hur, Tetrahedron Lett., 2013, 54, 1384.

22 V. Estévez, M. Villacampa and J. C. Menéndez, Chem. Commun., 2013, 49, 591.

23 V. Declerk, P. Nun, J. Martinez and F. Lamaty, Angew. Chem., Int. Ed., 2009, 48, 9318.

24 V. Štrukil, B. Barteloc, T. Portada, I. Đilović, I. Halasz and D. Margetić, Chem. Commun., 2012, 48, 12100.

25 J. Bonnamour, T.-X. Métro, J. Martinez and F. Lamaty, Green Chem., 2013, 15, 1116.
26 J. Schmeyers, F. Toda, J. Boy and G. Kaupp, J. Chem. Soc., Perkin Trans. 2, 1998, 989.

27 O. Dolotko, J. W. Wiench, K. W. Dennis, V. K. Pehcarsky and V. P. Balema, New J. Chem., 2010, 34, 25.

28 G. Kaupp, J. Schemeyers and J. Boy, J. Prakt. Chem., 2000, 342(3), 269.

29 J. Mokhtari, M. R. Naimi-Jamal, H. Hamzeali, M. G. Dekamin and G. Kaupp, ChemSusChem, 2009, 2, 248.

30 P. Nun, C. Martin, J. Martinez and F. Lamaty, Tetrahedron, 2011, 67, 8187.

31 N. Belkheri, B. Bougerne, F. Bedos-Beval, H. Duran, C. Bernis, R. Salvayre, A. Nègre-Salvayre and M. Baltas, Eur. J. Med. Chem., 2010, 45, 3019.

32 D. R. Dabideen, K. F. Cheng, B. Aljabari, E. J. Miller, V. A. Pavlov and Y. Al-Abed, J. Med. Chem., 2007, 50, 1993.

33 A. G. Silva, G. Zapata-Suto, A. E. Kummerle, C. A. M. Fraga, E. J. Barreiro and R. T. Sudo, Bioorg. Med. Chem., 2005, 13, 3431.

34 S. Rollas and Ş. G. Küçükgüzel, Molecules, 2007, 12, 1910.

35 B. P. Bandgar, V. S. Sadavarte, L. S. Uppalla and R. Govande, Monatsh. Chem., 2001, 132, 103.

36 M. Ješelnik, R. S. Varma, S. Polanc and M. Kočevar, Green Chem., 2002, 4, 35.

37 J.-P. Li, P.-Z. Zheng, J.-G. Zhu, R.-J. Liu and G.-R. Qu, S. Afr. J. Chem., 2006, 59, 90.

38 A. R. Hajipour, I. Mohammadpoor-Baltork and M. Bigdeli, $J$. Chem. Res. (S), 1999, 9, 570.

39 C. Vanucci-Bacqué, C. Carayon, C. Bernis, C. Camare, A. Nègre-Salvayre, F. Bedos-Belval and M. Baltas, Bioorg. Med. Chem., 2014, 22, 4269.

40 X. Ma, W. Yuan, S. E. J. Bell and S. L. James, Chem. Commun., 2014, 50, 1585.

41 A. E. Reed, L. A. Curtiss and F. Weinhold, Chem. Rev., 1988, 88, 899.

42 (a) A. D. Becke, J. Chem. Phys., 1993, 98, 5648; (b) C. Lee, W. Yang and R. G. Parr, Phys. Rev. B: Condens. Matter Mater. Phys., 1988, 37, 785.

43 M. J. Frisch, G. W. Trucks, H. B. Schlegel, G. E. Scuseria, M. A. Robb, J. R. Cheeseman, G. Scalmani, V. Barone, B. Mennucci, G. A. Petersson, H. Nakatsuji, M. Caricato, X. Li, H. P. Hratchian, A. F. Izmaylov, J. Bloino, G. Zheng, J. L. Sonnenberg, M. Hada, M. Ehara, K. Toyota, R. Fukuda, J. Hasegawa, M. Ishida, T. Nakajima, Y. Honda, O. Kitao, H. Nakai, T. Vreven, J. A. Montgomery Jr, J. E. Peralta, F. Ogliaro, M. Bearpark, J. J. Heyd, E. Brothers, K. N. Kudin, V. N. Staroverov, R. Kobayashi, J. Normand, K. Raghavachari, A. Rendell, J. C. Burant, S. S. Iyengar, J. Tomasi, M. Cossi, N. Rega, J. M. Millam, M. Klene, J. E. Knox, J. B. Cross, V. Bakken, C. Adamo, J. Jaramillo, R. Gomperts, R. E. Stratmann, O. Yazyev, A. J. Austin, R. Cammi, C. Pomelli, J. W. Ochterski, R. L. Martin, K. Morokuma, V. G. Zakrzewski, G. A. Voth, P. Salvador, J. J. Dannenberg, S. Dapprich, A. D. Daniels, Ö. Farkas, J. B. Foresman, J. V. Ortiz, J. Cioslowski, and D. J. Fox, Gaussian 09, Revision A.1, Gaussian, Inc., Wallingford CT, 2009. 
44 G. Rothenberg, A. P. Downie, C. L. Raston and J. L. Scott, J. Am. Chem. Soc., 2001, 123, 8701.

45 M. A. Mikhailenko, T. P. Shakhtsneider and V. V. Boldyrev, J. Mater. Sci., 2004, 39, 5435.

46 R. Kuroda, K. Higashiguchi, S. Hasebe and Y. Imai, CrystEngComm, 2004, 6, 463.

47 G. Kaupp, J. Schmeyers and J. Boy, Chemosphere, 2001, 43, 55.

48 G. Kaupp, CrystEngComm, 2003, 5, 117.

49 A. Jayasankar, A. Somwangthanaroj, Z. J. Shao and N. Rodríguez-Hornedo, Pharm. Res., 2006, 23, 2381.

50 M. Descamps, J. F. Willard, E. Dudognon and V. Caron, J. Pharm. Sci., 2007, 96, 1398.

51 S. Jabeen, T. J. Dines, S. A. Leharne, R. Withnall and B. Z. Chowdhry, J. Raman Spectrosc., 2010, 41, 1306.

52 T. Myazawa, J. Mol. Spectrosc., 1960, 4, 155.

53 S. Jabeen, R. A. Palmer, B. S. Potter, M. Helliwell, T. J. Dines and B. Z. Chowdhry, J. Chem. Crystallogr., 2009, 39, 151.

54 G. Rajalaksmi, V. R. Hathwar and P. Kumaradhas, Acta Crystallogr., Sect. B: Struct. Sci., Cryst. Eng. Mater., 2014, 70, 331.

55 L. H. Jensen, J. Am. Chem. Soc., 1954, 76, 4663.

56 N. B. Singh, R. J. Singh and N. P. Singh, Tetrahedron, 1994, 50(22), 6441.
57 (a) A. Gavezzotti, J. Am. Chem. Soc., 1983, 105, 5220; (b) A. Gavezzotti, Tetrahedron, 1987, 43, 1241.

58 J. A. R. P. Sarma, A. Nagaraju, K. K. Majumdar, P. M. Samuel, I. Das, S. Roy and A. J. McGhie, J. Chem. Soc., Perkin Trans. 2, 2000, 1119.

59 K. S. McKissic, J. T. Caruso, R. G. Blair and J. Mack, Green Chem., 2014, 16, 1628.

60 A. A. L. Michalchuk, I. A. Tumanov and E. V. Boldyreva, CrystEngComm, 2013, 15, 6403.

61 I. A. Tumanov, A. F. Achkasov, E. V. Boldyreva and V. V. Boldyrev, CrystEngComm, 2011, 13, 2213.

62 S. T. Collom, P. T. Anastas, E. S. Beach, R. H. Crabtree, N. Hazari and T. J. Sommer, Tetrahedron Lett., 2013, 54, 2344.

63 S. S. M. Konda, J. N. Brantley, B. T. Varghese, K. M. Wiggins, C. W. Bielawski and D. E. Makarov, J. Am. Chem. Soc., 2013, 135,12722 .

64 M. T. Ong, J. Leiding, H. Tao, A. M. Virshup and T. J. Martinez, J. Am. Chem. Soc., 2009, 131(18), 6377.

65 J. Ribas-Arino, M. Shiga and D. Marx, Angew. Chem., Int. Ed., 2009, 48, 4190.

66 C. R. Hickenboth, J. S. Moore, S. R. White, N. R. Sottos, J. Baudry and S. R. Wilson, Nature, 2007, 446, 423.

67 N. Haruta, T. Sato, K. Tanaka and M. Baron, Tetrahedron Lett., 2013, 54, 5920. 